\title{
Cell-in-cell phenomenon: leukocyte engulfment by non-tumorigenic cells and cancer cell lines
}

Mareike F. Bauer ${ }^{1}$, Michael Hader ${ }^{1}$, Markus Hecht ${ }^{1}$, Maike Büttner-Herold ${ }^{2}$, Rainer Fietkau ${ }^{1}$ and Luitpold V. R. Distel ${ }^{\text {* }^{*} \text { (D) }}$

\begin{abstract}
Background: Research on cell-in-cell (CIC) phenomena, including entosis, emperipolesis and cannibalism, and their biological implications has increased in recent years. Homotypic and heterotypic engulfment of various target cells by numerous types of host cells has been studied in vitro and in tissue sections. This work has identified proteins involved in the mechanism and uncovered evidence for $\mathrm{ClC}$ as a potential histopathologic predictive and prognostic marker in cancer. Our experimental study focused on non-professional phagocytosis of leukocytes.
\end{abstract}

Results: We studied the engulfment of peripheral blood mononuclear cells isolated from healthy donors by counting CIC structures. Two non-tumorigenic cell lines (BEAS-2B, SBLF-9) and two tumour cell lines (BXPC3, ICNI) served as host cells. Immune cells were live-stained and either directly co-incubated or treated with irradiation or with conventional or microwave hyperthermia. Prior to co-incubation, we determined leukocyte viability for each batch via Annexin V-FITC/propidium iodide staining.

All host cells engulfed their targets, with uptake rates ranging from $1.0 \% \pm 0.5 \%$ in $\mathrm{BxPC} 3$ to $8.1 \% \pm 5.0 \%$ in $\mathrm{BEAS}-2 \mathrm{~B}$. Engulfment rates of the cancer cell lines BXPC3 and ICNI (1.6\% $\pm 0.2 \%)$ were similar to those of the primary fibroblasts SBLF-9 $(1.4 \% \pm 0.2 \%)$. We found a significant negative correlation between leukocyte viability and cell-incell formation rates. The engulfment rate rose when we increased the dose of radiotherapy and prolonged the impact time. Further, microwave hyperthermia induced higher leukocyte uptake than conventional hyperthermia. Using fluorescent immunocytochemistry to descriptively study the proteins involved, we detected ring-like formations of diverse proteins around the leukocytes, consisting, among others, of a-tubulin, integrin, myosin, Factin, and vinculin. These results suggest the involvement of actomyosin contraction, cell-cell adhesion, and the atubulin cytoskeleton in the engulfment process.

Conclusions: Both non-tumorigenic and cancer cells can form heterotypic CIC structures by engulfing leukocytes. Decreased viability and changes caused by microwave and X-ray irradiation trigger non-professional phagocytosis.

Keywords: Cell-in-cell, Non-professional phagocytosis, Cannibalism, Leukocyte engulfment

\footnotetext{
* Correspondence: Luitpold.Distel@uk-erlangen.de

'Department of Radiation Oncology, Universitätsklinikum Erlangen,

Friedrich-Alexander-Universität Erlangen-Nürnberg (FAU), Universitätsstraße

27, D-91054 Erlangen, Germany

Full list of author information is available at the end of the article
}

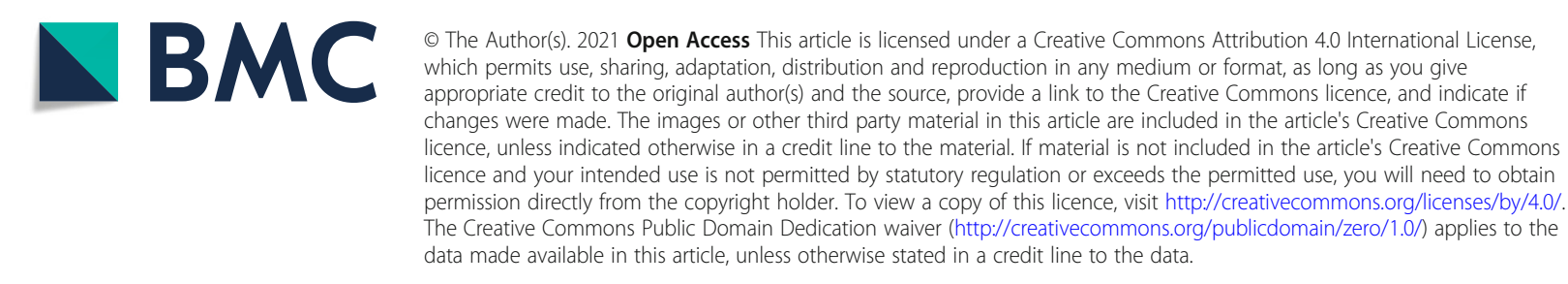




\section{Background}

In recent years, a field of science has grown up around a phenomenon long known of, but previously largely overlooked: cell-in-cell (CIC) structures. The term refers to a phenomenon whereby one cell is inside another [1] as a result of non-professional phagocytosis [2]. Cell-incell structures can arise from the interactions of cells of the same cell type (homotypic CIC) or different cell types (heterotypic CIC). Entosis, emperipolesis and cannibalism are three manifestations of this phenomenon, each of which features differences in the formation mechanisms and biological impact of cell-in-cell structures [1].

Entosis is the homotypic active invasion of one cell into another. In addition to cell-cell adhesion, entosis requires a contractile force [3] and a connecting sensor to trigger the uptake [4]. The engulfment of living leukocytes by other cells is called emperipolesis [5]. Cannibalism is defined as the ability of a cancer cell to engulf living or dead cells or even amorphous material [1]. A complex set of factors, pertaining both to the host cell and to the engulfed cell, regulates all three of these phenomena [6]. Actomyosin cytoskeleton rearrangements, cell-cell adhesion and a mechanosensitive interfacing ring [4] are some of the key players in non-professional phagocytosis $[1,4,7,8]$.

Cell-in-cell structures are part of physiological processes, such as cell maturation $[7,9]$ tissue development [10] and homeostasis [11], and also occur in pathological processes, namely inflammation [12] and tumour formation $[9,11,13]$. Identifying and understanding the biological effects of cell-in-cell structures in cancer has become a focal area of research.

Non-professional phagocytosis can generate distinctly divergent, indeed opposing effects in the emergence of tumours. It can support tumour development and progression, serving to supply nutrients and giving the host a survival advantage $[1,6,14,15]$. The invasion of one cell into another can lead to multinucleation, promoting aneuploidy and malignant degeneration [11, 13]. The formation of cell-in-cell structures also acts as a selection mechanism for the most malignant clones, as they are more potent phagocytes than are less malignant clones [16]. Further, tumour cells establish an immune escape mechanism by engulfing targeting immune cells $[11,15,17]$. This alters the tumour microenvironment [13]. However, non-professional phagocytosis also fulfils a tumour-suppressive role. It can clear aberrant cells from tissues and thereby prevent aneuploidy and cancerous degeneration $[8,18]$. It can also prevent the formation of metastases by clearance of matrix-detached cells [15]. Additionally, incorporated immune cells can cause host cell death through cytotoxic effects released inside the host cell $[9,19]$.
Notwithstanding this ambiguity in the biological impact of cell-in-cell structures, Fais and Overholtzer have declared them a "hallmark of cancer" [1]. Studies on cell-in-cell structures in various tumours point to CIC as a potential histopathologic predictive or prognostic marker for cancer [20-27].

Against this backdrop, our experimental study aimed to shed light on the role of leukocytes in nonprofessional phagocytosis. Due to the assertion that nonprofessional phagocytosis is a characteristic of malignant clones [1, 13, 14, 28], we focussed on leukocyte interaction with both non-tumorigenic and tumour tissue cells in vitro to determine differences between malignant and non-malignant cells. In addition, our study sought to establish whether engulfment differs in accordance with the viability of target cells. This study uses the term "leukocytes" as a synonym for isolated peripheral blood mononuclear cells (PBMC).

\section{Results \\ Non-tumorigenic tissue and cancer cell lines have the capacity to engulf leukocytes}

Recent experiments run in our laboratory found that dead target cells resulted in a higher rate of homotypic non-professional phagocytosis [29]. Assuming heterotypic non-professional phagocytosis has similar properties, we initially used leukocytes exposed to $56^{\circ} \mathrm{C}$ hyperthermia as target cells.

All recipient cell lines studied were able to engulf hyperthermia-treated leukocytes. However, they showed differing capacities for engulfment. CIC rates ranged from $8.1 \% \pm 5.0 \%$ in the immortalised human lung epithelial cell line BEAS-2B to $1.0 \% \pm 0.5 \%$ in the human primary pancreatic adenocarcinoma cell line BxPC3. The engulfment capacity of BEAS-2B was significantly higher than the capacity of $\operatorname{BxPC} 3(p=0.005)$. The cancer cell lines $\mathrm{BxPC} 3$ and ICNI $(1.6 \% \pm 0.2 \%)$ engulfed the leukocytes at a similar rate as did the human primary fibroblasts SBLF-9 $(1.4 \% \pm 0.2 \%)$ (Fig. 1 and Table 1$)$.

As we had obtained low CIC rates for SBLF-9, BxPC3 and ICNI, we decided to perform further experiments with BEAS-2B as host cells. We hoped these experiments would enable us to determine differences between treatments applied previous to co-incubation.

\section{Inverse correlation between $\mathrm{CIC}$ rate and leukocyte viability}

Living leukocytes were co-incubated with BEAS-2B for $12 \mathrm{~h}, 24 \mathrm{~h}, 36 \mathrm{~h}$ or $48 \mathrm{~h}$. The viability of the leukocytes declined from $90.0 \% \pm 2.2 \%$ at $12 \mathrm{~h}$ to $81.3 \% \pm 3.5 \%$ at $48 \mathrm{~h}$ (Fig. 2A), which implies that the vital leukocytes died over time at a certain rate (Fig. 2B). However, the $\mathrm{CIC}$ rate varied only marginally over time (Fig. $2 \mathrm{C}$ ). 


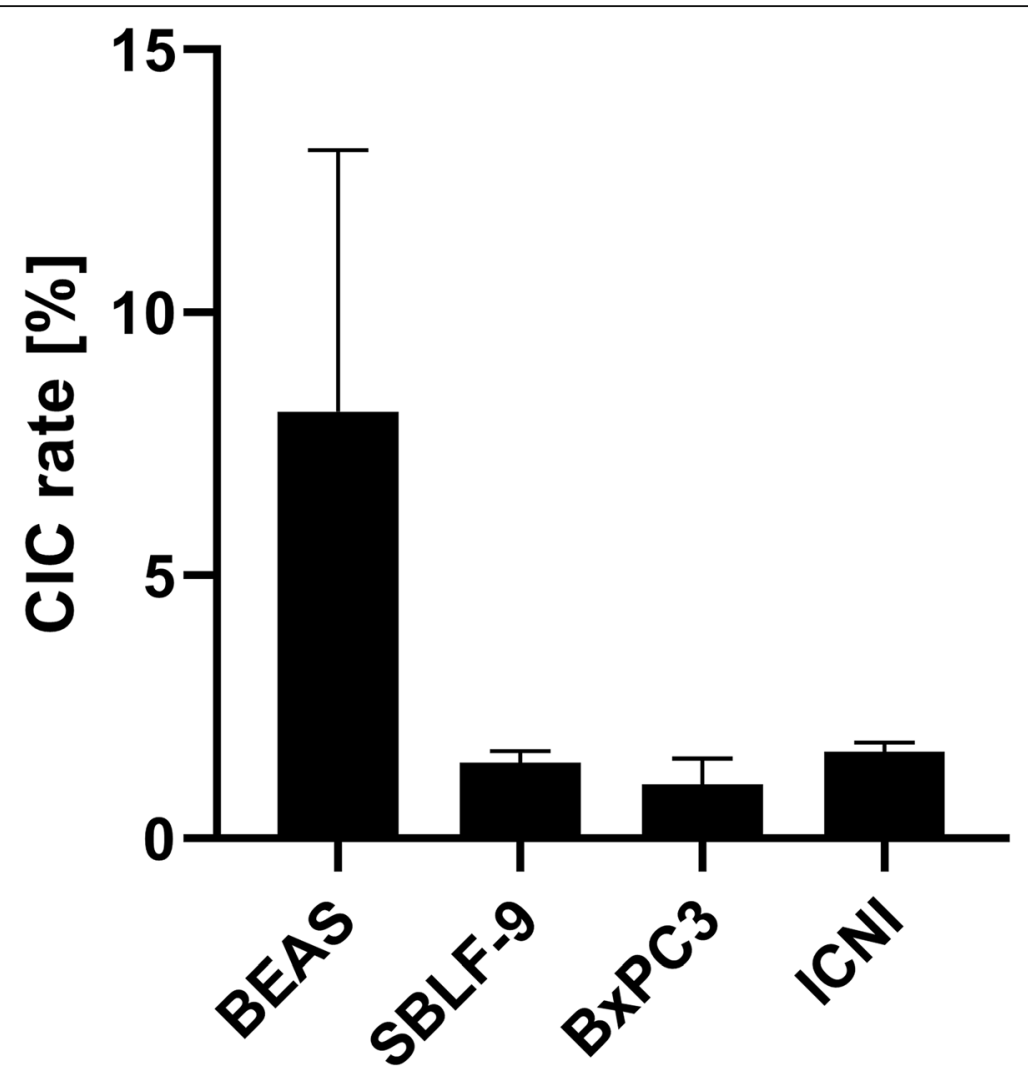

Fig. 1 Non-professional uptake of leukocytes into different host cells lines. Heated $\left(56^{\circ} \mathrm{C}, 40 \mathrm{~min}\right)$ leukocytes are co-incubated for $4 \mathrm{~h}$ with adherent epithelial lung cells (BEAS-2B), primary human fibroblasts (SBLF-9), pancreatic cancer cells (BXPC3) and melanoma cells (ICNI). The leukocytes have been isolated from whole blood residues from platelet donations and from EDTA tubes from healthy blood donors. A KruskalWallis test detects a significant difference between the phagocytic capacities of BEAS-2B and BxPC3 $(p=0.005)$

Overall, we found significant positive correlations between CIC rates and both apoptotic ( $p=0.021$, Fig. 2D) and necrotic rates $(p<0.001$, Fig. $2 \mathrm{E})$, as well as a significant negative correlation between CIC rates and viability $(p<0.001$, Fig. 2F). It appears, therefore, that dying and dead leukocytes are more susceptible to targeting by non-professional phagocytosis.

\section{$\mathrm{CIC}$ rate depends on irradiation dose and impact time}

We tested various treatments prior to co-incubation in order to determine whether the cause of cell death impacts engulfment. The leukocytes were irradiated with $0.5 \mathrm{~Gy}, 1 \mathrm{~Gy}, 2 \mathrm{~Gy}$ or $5 \mathrm{~Gy}$, then incubated for $18 \mathrm{~h}$ and 36 $\mathrm{h}$ to ensure that the damage caused by irradiation could progress prior to co-incubation [30,31]. The viability of untreated leukocytes after $18 \mathrm{~h}$ or $36 \mathrm{~h}$ respectively served as negative controls. As the engulfment rate of

Table 1 Heterotypic engulfment capacity of each cell line

\begin{tabular}{lllll}
\hline & BEAS-2B & SBLF-9 & BxPC3 & ICNI \\
\hline Mean & $8.1 \%$ & $1.4 \%$ & $1.0 \%$ & $1.6 \%$ \\
Standard deviation & $5.0 \%$ & $0.2 \%$ & $0.5 \%$ & $0.2 \%$ \\
\hline
\end{tabular}

untreated leukocytes remained mostly constant from $4 \mathrm{~h}$ (neg. Control Fig. 4A) to $48 \mathrm{~h}$ (Fig. 2C), we did not perform additional negative control experiments for CIC rates at $18 \mathrm{~h}$. With an increasing dose of irradiation, the leukocytes' viability rate decreased, while apoptotic and necrotic rates increased. Death rates also rose with latency, as cells had more time to undergo apoptosis as a response to irradiation damage (Fig. 3A). After an impact time of $18 \mathrm{~h}$, the CIC rate varied only marginally, whereas it increased in line with irradiation dose after an impact time of $36 \mathrm{~h}$ (Fig. 3B). This means that no correlation between $\mathrm{CIC}$ rate and death rate was observed after an impact time of $18 \mathrm{~h}(p=0.375$, Fig. 3C), but after an impact time of $36 \mathrm{~h}$, a significant positive correlation between $\mathrm{CIC}$ rate and death rate emerged $(p=0.042$, Fig. 3D).

\section{Microwave irradiation increases both death rate and $\mathrm{CIC}$} rate

A number of research groups have found non-thermal effects of microwave irradiation on cells [32-34]. We investigated whether these effects also manifested in nonprofessional phagocytosis of leukocytes. The leukocytes 


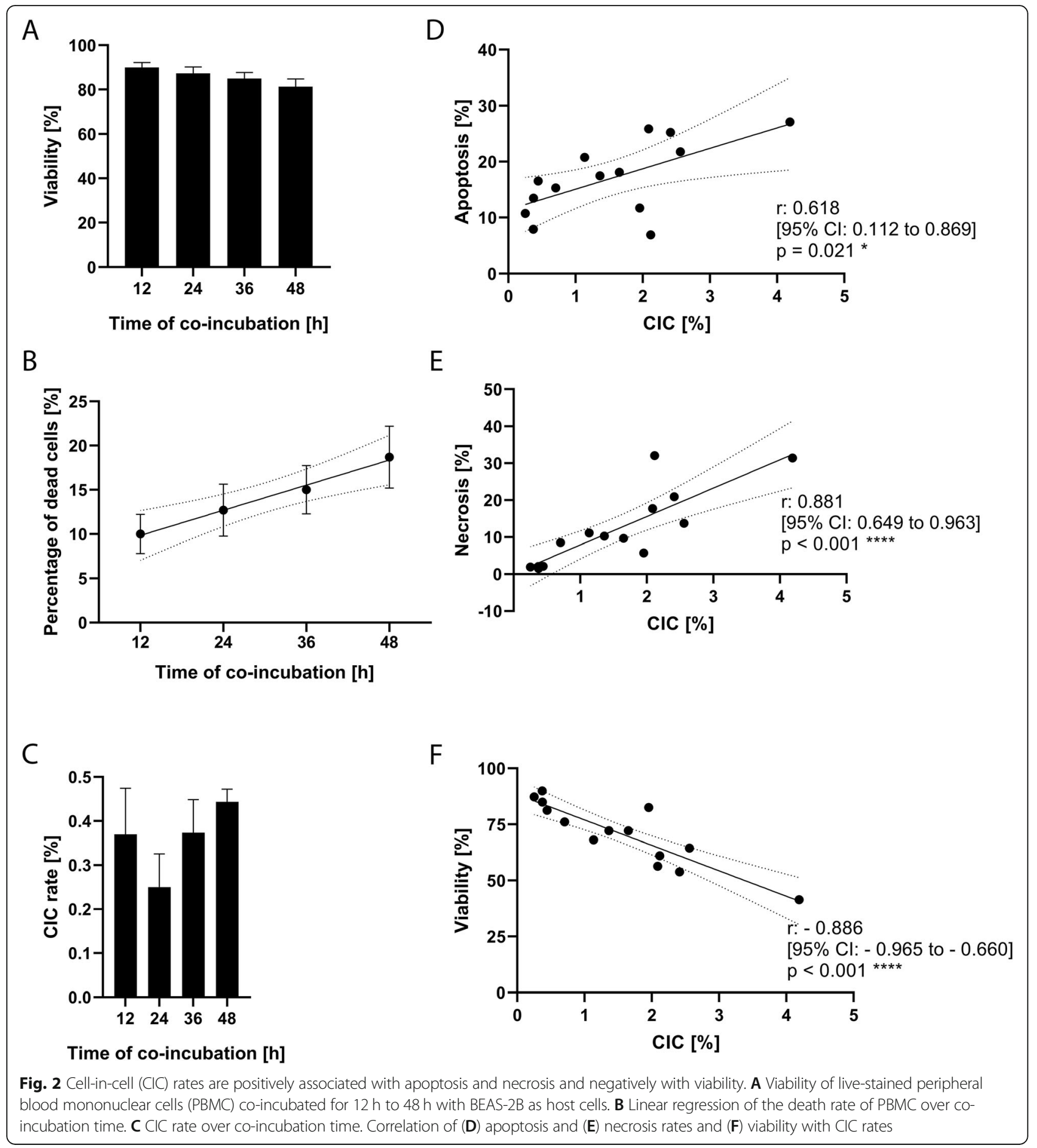

were exposed to $44{ }^{\circ} \mathrm{C}$, generated either by microwave irradiation or water bath, for a period of $1 \mathrm{~h}$. Viability and CIC rates after $4 \mathrm{~h}$ of co-incubation were compared. Viability and $\mathrm{CIC}$ rates of untreated leukocytes at the same points in time served as negative controls. Overall death rates induced by conventional hyperthermia and microwave hyperthermia did not differ significantly (Fig. 4A). However, differences did appear between apoptosis and necrosis rates. Conventional hyperthermia resulted in around twice as much apoptosis as necrosis. By contrast, microwave irradiation led to nearly 5 times more necrosis than apoptosis. The CIC rates were $2.12 \% \pm 1.26 \%$ after microwave irradiation and $0.70 \% \pm 0.33 \%$ after treatment with conventional hyperthermia (Fig. 4B). This difference was not significant. 


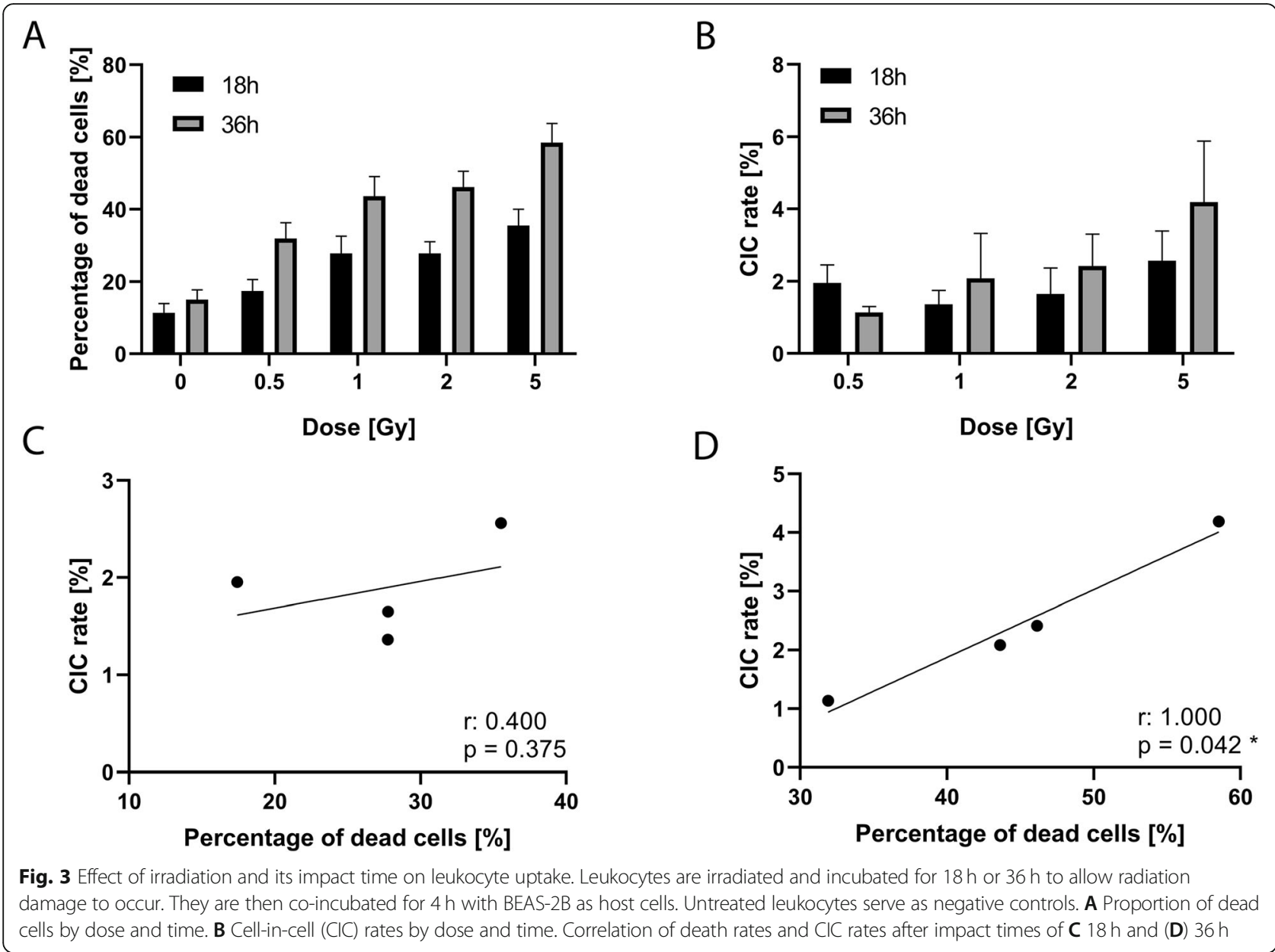

Various proteins form a ring-like structure around the leukocyte during and after engulfment

Detection of proteins involved in cell-in-cell formation proceeded via immunofluorescence microscopy. We used PBMC as target cells and BEAS-2B as host cells, and analysed cytoskeletal proteins and proteins involved in cell-cell adhesion. In $\alpha$-tubulin staining, a ring formed around the leukocyte during every stage of the uptake (Fig. 5B). This ring was connected to extensions of the $\alpha$-tubulin cytoskeleton of the engulfing cell (Fig. 5C). The internalising cell seemed to pull in the leukocyte from the opposite pole of the nucleus. The ring-like $\alpha$-tubulin condensation around the leukocyte remained visible after engulfment was complete (Fig. 5D). An X-Y-Z scan image illustrates the complete engulfment of a leukocyte by an $\alpha$-tubulin-stained BEAS-2B cell (Fig. 5E).

Further, $\beta$-integrin formed a ring around the leukocyte during engulfment, with agglomeration at the contact side (Fig. 6). Similar ring-like protein condensations were observed in $\beta$-catenin, p-ezrin, FAT, fibronectin and vinculin staining (Fig. 6).

As the F-actin cytoskeleton and myosin cytoskeleton are key players in professional phagocytosis, we also studied these proteins (Fig. 7). Both formed a ring-like structure around the leukocyte, like the ones described above. Further, a slight connection to the actomyosin cytoskeleton of the outer cell was occasionally visible. However, we did not observe the pseudopods of the actin cytoskeleton that are typical of professional phagocytosis.

\section{Discussion}

The cancer cell lines used in this study formed CIC structures by engulfing leukocytes, thus exhibiting behaviour consistent with that found by other authors $[14,17,19,26,27,35]$. The non-tumorigenic cell lines SBLF-9 and BEAS-2B also engulfed leukocytes under normal cell culture conditions. In line with the findings of previous work [14, 28], primary human melanoma cells did not exhibit high phagocytic potential in this study. Their CIC rate did not differ from the CIC rate of human primary skin fibroblasts. It therefore appears that malignant transformation alone is insufficient to increase the phagocytic capacity of skin cells. In accordance with the findings of $\mathrm{He}$ et al. [36], we assume that differences in host tumour cell biology play a role in leukocyte- 

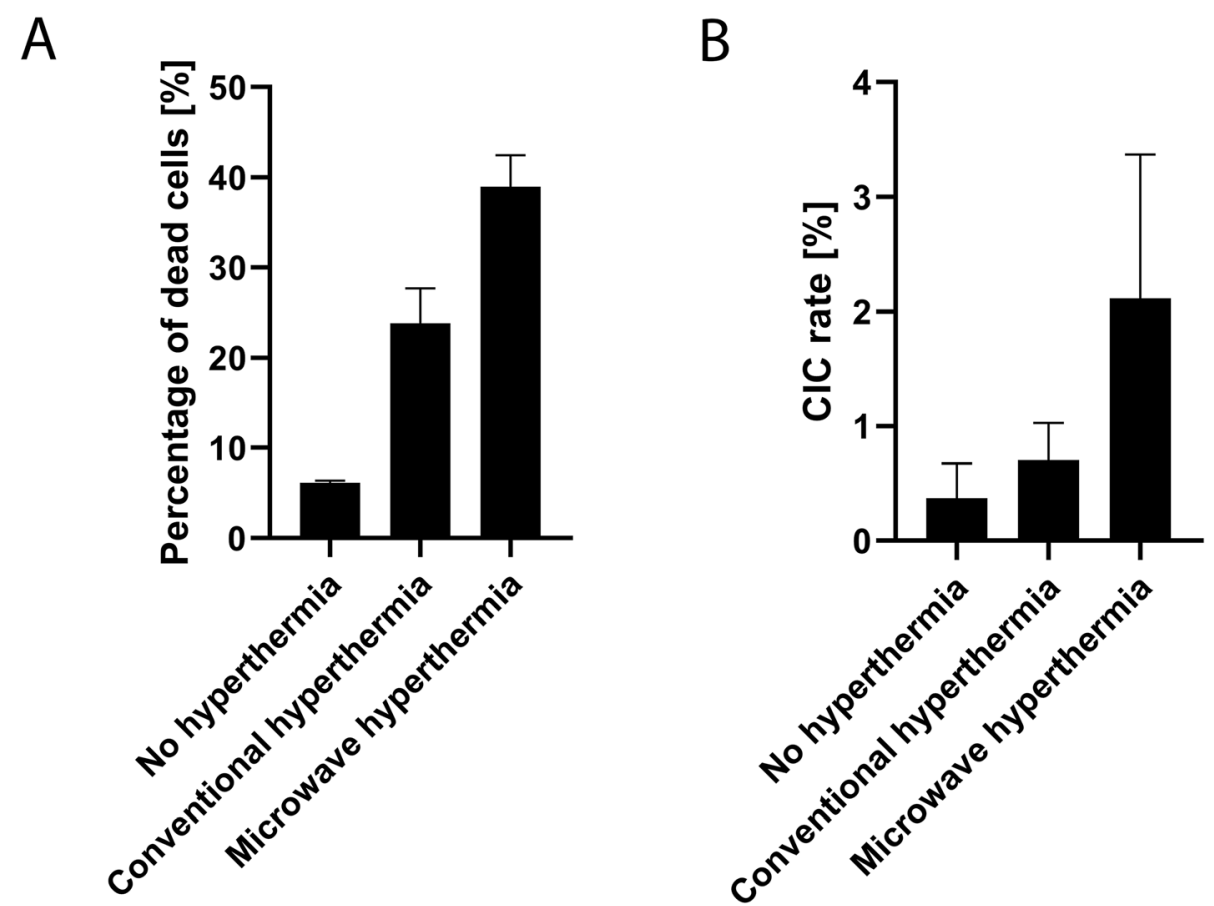

Fig. 4 Comparison of conventional and microwave hyperthermia. Leukocytes are exposed to conventional hyperthermia via water bath or microwave hyperthermia at $44^{\circ} \mathrm{C}$ for $1 \mathrm{~h}$. Leukocytes not exposed to hyperthermia are the negative control. A Cell death rates and $\mathbf{B} \mathrm{CIC}$ rates are determined after $4 \mathrm{~h}$ of co-incubation

tumour cell interaction and may explain the observed differences in phagocytic capacities.

As the BEAS-2B host cells engulfed live as well as apoptotic and necrotic leukocytes, our experimental setting most likely resembles the phenomenon called "cannibalism". In a similar way to the BEAS-2B host cells, cannibalistic cancer cells do not discriminate between living and dead cells and even engulf amorphous material $[1,28,37]$; this notwithstanding, in our experiments dead cells were more likely to be targets of engulfment. As the dead cells lay motionless on the host cell layers, they may have sunk into the host cells, in a manner similar to the description of cancer cell cannibalism by Stefano Fais [37]. The fact that living cells retain their movement may explain the higher engulfment rates for dead cells.

Besides a decrease in viability, the CIC rate also depended on other factors. After X-ray and microwave irradiation, leukocyte engulfment rates were comparable at similar death rates. Untreated leukocytes and those exposed to hyperthermia in a water bath were much less frequently engulfed than irradiated leukocytes at similar death rates. It appears, then, that non-thermal effects of microwave irradiation [32-34] and cellular effects and changes caused by $\mathrm{X}$-ray irradiation also trigger leukocyte engulfment.

Although the mechanism behind our experimental setting predominantly resembles cannibalism, the changes we observed at protein level also show parallels to entosis. In what follows, we will therefore review our findings in the light of the various mechanisms of uptake described in the literature.

As shown by Xia et al., microtubules are important for entosis and disturbing them will disrupt cell-in-cell formation [38]. In the present study, we also observed structural changes of $\alpha$-tubulin during cell-in-cell formation. The $\alpha$-tubulin cytoskeleton deformed around the leukocyte or appeared to "pull it in". Our findings therefore indicate involvement of the microtubule cytoskeleton in the process of non-professional phagocytosis.

Alongside its role in cellular plasticity, the microtubule cytoskeleton affects the stiffness of the cell, as does the actomyosin cytoskeleton [16, 38-40]. Actomyosin is concentrated inside the internalised cell, particularly opposite the adhesion contacts, and represents the contractile force responsible for invasion of the host cell $[16,39]$. Fluorescent immunocytochemistry has consistently revealed actomyosin enhancement at the cell membrane of the leukocyte. As a large number of leukocytes in our experiments were necrotic, we assume that an active invasion process, as occurs in entosis [3], is improbable here. This notwithstanding, the stiffness of the leukocytes may be increased, possibly by passive myosin enhancement, which may have precipitated engulfment of that leukocyte.

Research has proposed that adherens junctions act as sensors of cellular stiffness in cell-in-cell formation, 


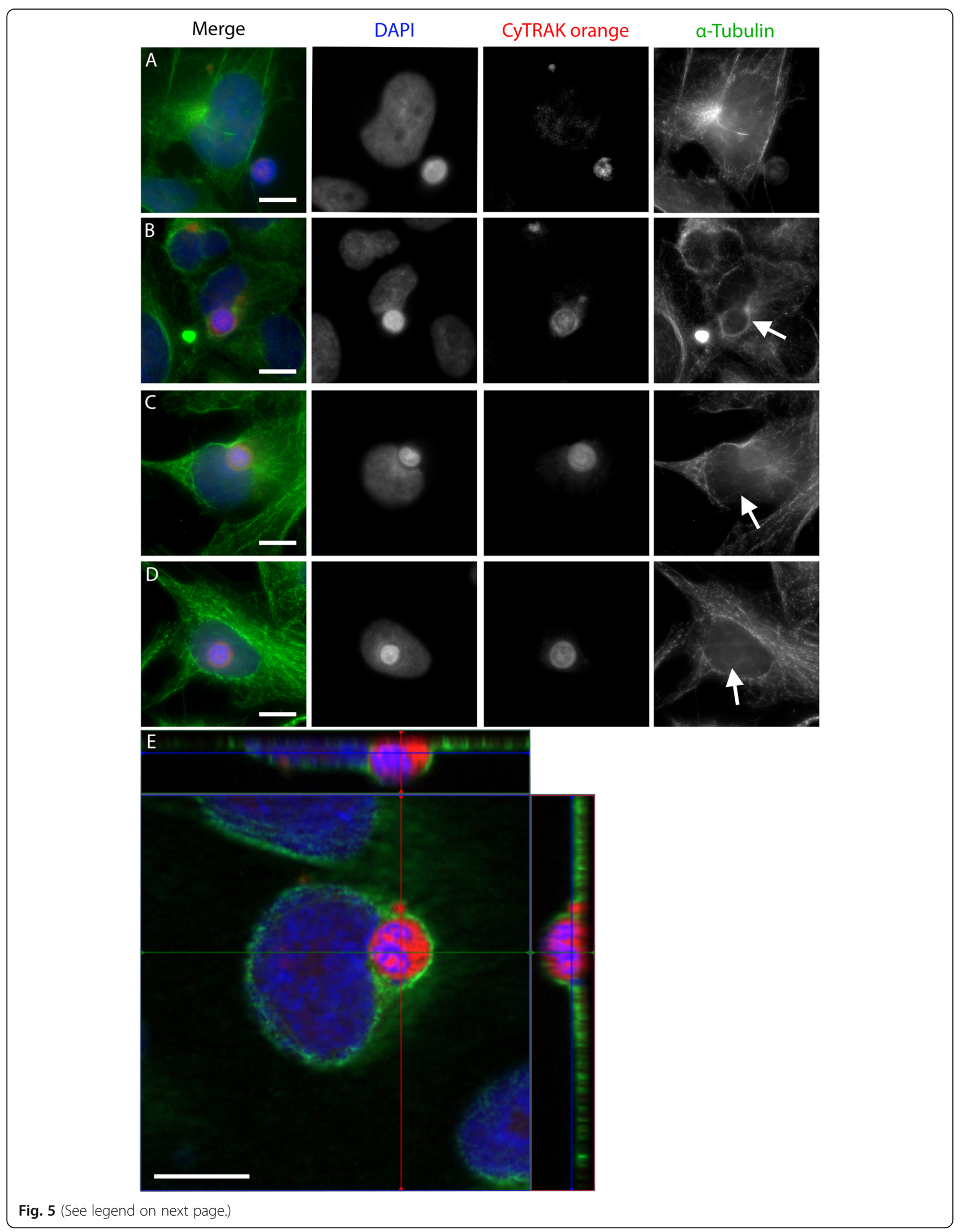


(See figure on previous page.)

Fig. 5 Role of a-tubulin in leukocyte uptake. a-Tubulin is stained using a specific primary antibody and Alexa Fluor 488 secondary antibody. CyTRAK orange is the live dye used to stain peripheral blood mononuclear cells before co-incubation with BEAS-2B as host cells. The nuclei are stained with DAPI. The figure displays several stages of engulfment of leukocytes by BEAS-2B, as a representative sample of $>150 \mathrm{CIC}$ structures analysed: $\mathbf{A}$ atubulin cytoskeleton of a BEAS-2B host cell and a leukocyte before internalisation. B Establishment of a link between target and host cell; arrow marks ring-like condensation around leukocyte. C Host cell nucleus deformation; arrow demonstrates connection between a-tubulin ring and cytoskeleton of recipient cell. D Complete engulfment of the leukocyte by a BEAS-2B cell; arrow indicates ring-like structure still present around engulfed leukocyte. $\mathbf{E}$ Merged X-Y-Z scan of a representative cell-in-cell structure shows complete engulfment of leukocyte. Scale bars indicate $10 \mu \mathrm{m}$

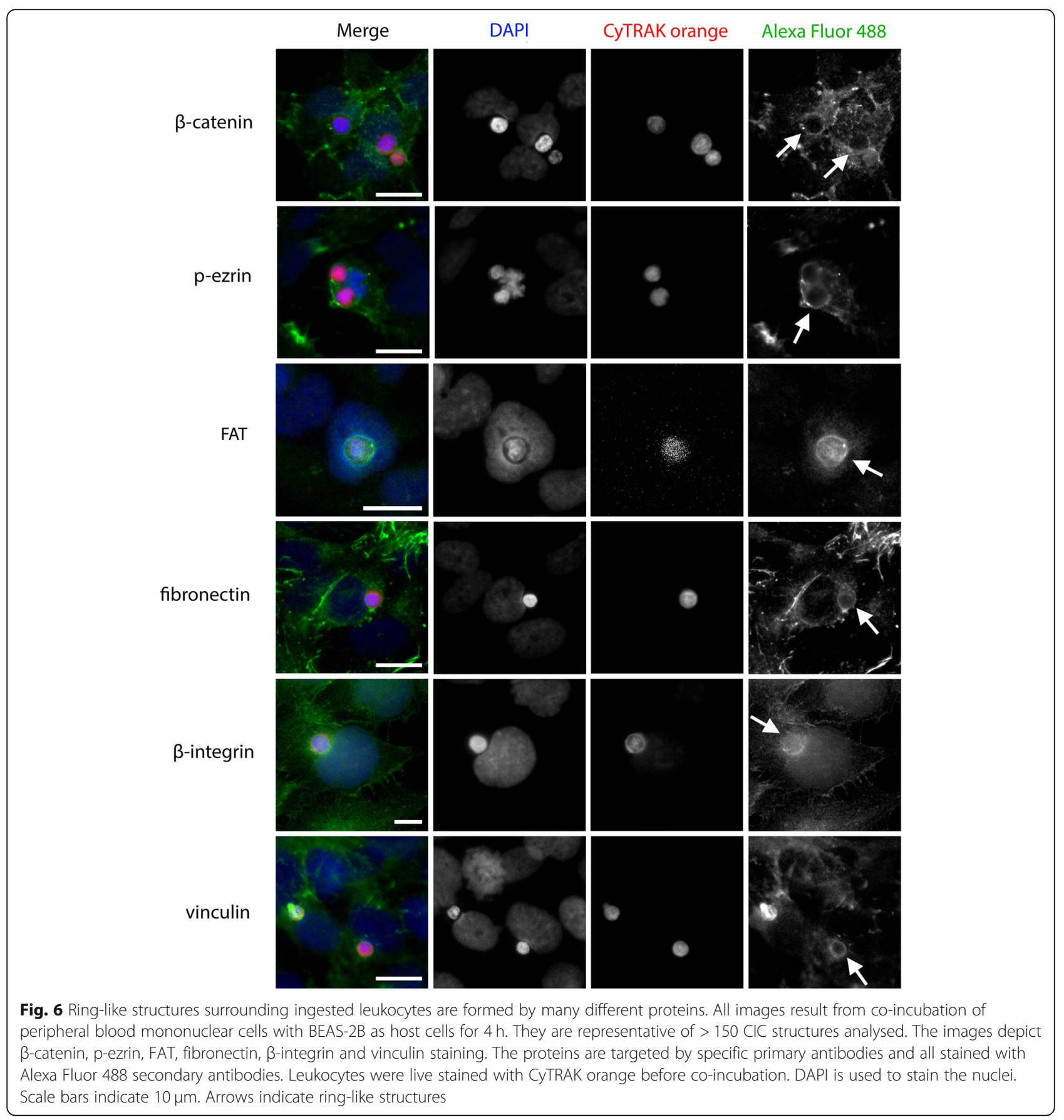



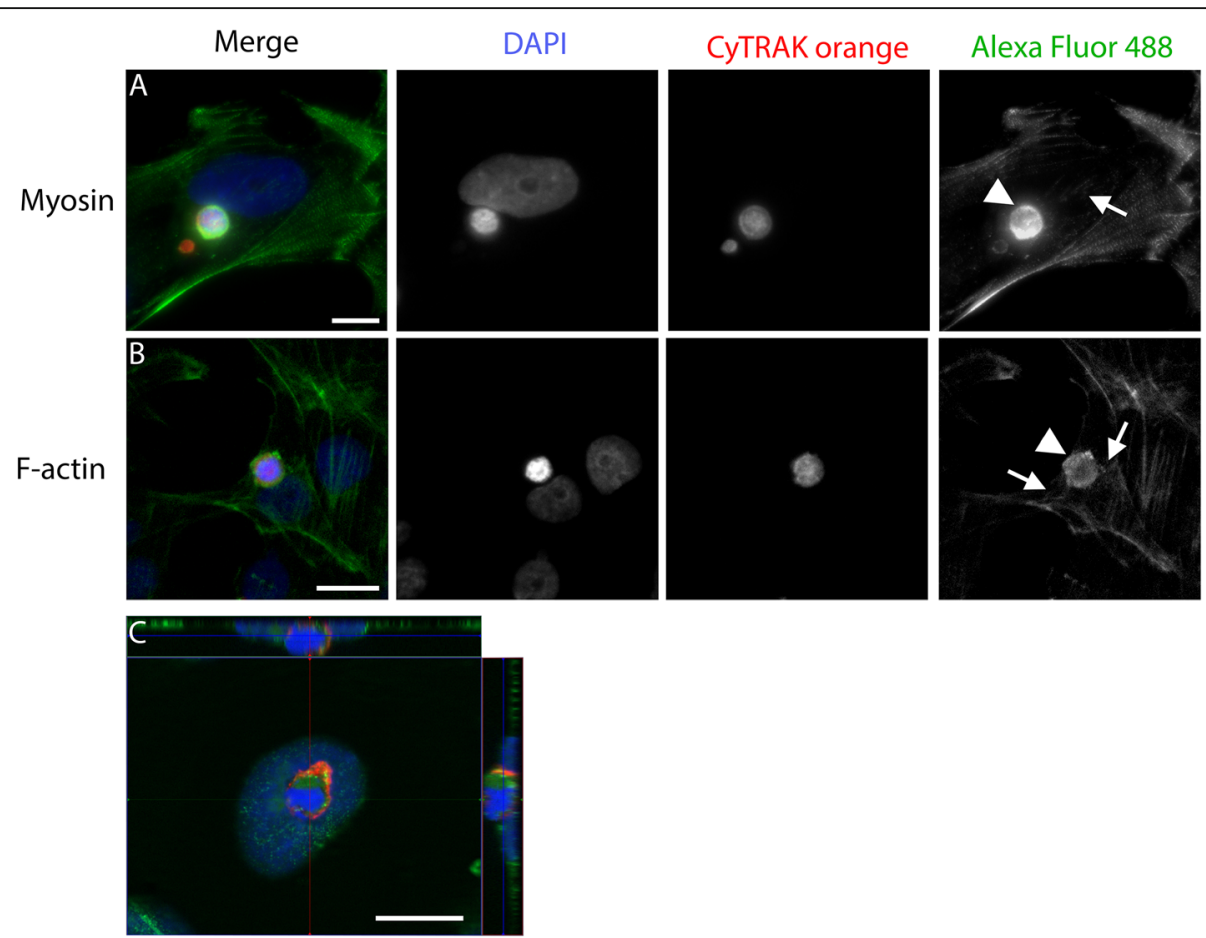

Fig. 7 Actomyosin distribution during non-professional phagocytosis. Peripheral blood mononuclear cells are stained with CyTRAK orange before co-incubation with BEAS-2B for $4 \mathrm{~h}$. Nuclei are stained using DAPI. A Myosin staining is performed using a secondary antibody coupled with Alexa Fluor 488. B Actin is visualised using phalloidin. The images shown here are representative of $>150 \mathrm{CIC}$ structures analysed. C Merged X-YZ scan of myosin-stained cell-in-cell structure to demonstrate the complete engulfment of the leukocyte. Scale bars indicate $10 \mu \mathrm{m}$. Arrowheads indicate ring-like structures; arrows indicate interactions with the cytoskeleton of the engulfing cell

thereby mediating entosis [8]. Vinculin is one of the linkers between adherens junctions and the actomyosin cytoskeleton $[4,8]$. In our experiments, vinculin was condensed around the internalised leukocyte in a ringlike structure. This ring may be a two-dimensional representation of the mechanosensitive formation of vinculin with other proteins described by Wang et al., which is required for leukocyte engulfment [4]. One of the proteins involved could be $\beta$-catenin, as it was distributed in a similar manner to vinculin both in Wang et al. [4] and in our experiments. However, the ring-like $\beta$-catenin formation around the leukocytes could also indicate that the leukocytes reside inside a vacuole formed by the cell membrane of the engulfing cells [19].

Various integrins mediate cell-cell adhesions, for example in leukocyte transcytosis [41, 42], or in epithelial to mesenchymal transition, a prerequisite for cancer cell invasion and metastasis formation [43]. Sexton et al. demonstrated that integrins participate in the detection of apoptotic leukocytes, which leads to their engulfment [44]. They also described an integrin enhancement around the target cell [44]. In our experiments, $\beta$ integrin was condensed at the contact sides between the target and host cell at an early stage of the engulfment. Once the leukocyte was completely engulfed, the $\beta$ - integrin formed a ring-like structure around it. This may indicate the formation of focal adhesions $[43,44]$ prior to engulfment as means of cell-cell contact.

Fibronectin is one of the proteins that interact with integrins [45]. It is involved in cell-matrix attachment, cell-cell adhesion $[45,46]$ and phagocytosis, especially of bacteria [47]. In our experiments, fibronectin formed ring-like structures around the leukocytes, suggesting it could be displayed at their surface [46]. This display may have been triggered by hyperthermia treatment or similar stress factors, resulting in a form of leukocyte activation [46] prior to cell death. This could mediate non-professional phagocytosis via interaction with host cell integrins.

The actin cytoskeleton's linker protein, ezrin, also takes part in non-professional phagocytosis [28, 35]. It is distributed around the internalised particle [28]; in our case it formed a ring-like structure around the leukocytes. The inhibition of ezrin greatly impairs the phagocytic capacity of tumour cells $[28,35]$. Our findings suggest that ezrin is part of the regulatory mechanisms of non-professional phagocytosis by non-tumorigenic cells. We would recommend that future studies in this area focus on differences in ezrin levels and ezrin's phosphorylation in cells with high versus low phagocytic 
capacity, as phosphorylation patterns may potentially explain the disparity [28].

Another protein involved in the regulation of actin cytoskeleton transitions is FAT1 [48]. This is a transmembrane protein from the cadherin superfamily, particularly expressed in epithelial cell lines. FAT1 has been shown to mediate cell-cell adhesion [48]. Further, it can bind to $\beta$-catenin [49]. This may explain why we found a similar distribution of FAT1 and $\beta$-catenin. The exact role of FAT1 in the interplay of cytoskeleton rearrangement and cell-cell adhesion remains to be identified.

\section{Conclusion}

This study's findings are indicative of the ability of nontumorigenic and cancer cells to engulf leukocytes and form heterotypic cell-in-cell structures. They also suggest that the phagocytic potential of a cell line does not solely depend on its malignant transformation, but additionally on a complex set of biological factors not analysed here. In our experiments, decreased viability and exposure to X-ray and microwave irradiation increased rates of non-professional phagocytosis.

\section{Methods}

\section{Cell culture}

We studied the phagocytic capacity of two nontumorigenic and two cancer cell lines. As non-tumorigenic cell lines, we used BEAS-2B, a virus-transformed epithelial lung cell line, and SBLF-9, a primary skin fibroblast cell line. The cancer cell lines chosen were BxPC3, a human pancreatic adenocarcinoma cell line, and ICNI, a human melanoma cell line. Other studies conducted in our laboratory had found BEAS-2B, several primary skin fibroblast cell lines and BxPC3 to display homotypic nonprofessional phagocytosis $[29,50]$. BxPC3 and a primary skin fibroblast cell line also engulfed heterotypic cells [50]. In addition to this, the work of $\mathrm{He}$ et al. demonstrated the ability of BxPC3 to engulf leukocytes [36]. On this basis, we expected these three cell lines to be most likely to engulf leukocytes. Lugini et al. demonstrated the ability of metastatic melanoma cells to engulf leukocytes both in vivo and in vitro [14]. In light of this finding, we included a human melanoma cell line in our study. Our aim in including both primary human fibroblast and melanoma cell lines was to directly compare the uptake capacity of healthy tissue to that of tumour tissue.

Host cells were cultured adherently on glass coverslips in 6-well plates at $37{ }^{\circ} \mathrm{C}$ in a $5 \% \mathrm{CO}_{2}$ atmosphere, reaching a confluent layer of approximately 200,000 cells at the time of co-incubation. We used individually composed media, comprising different amounts of F-12 Medium, Dulbecco's Modified Eagle's Medium, foetal calf serum (FCS) and variable additives, including 1\% penicillin/streptomycin antibiotics.

\section{Isolation of leukocytes from peripheral blood}

Peripheral blood mononuclear cells (PBMC) were used as target cells. They were isolated both from whole blood residues from platelet donations and from EDTA (ethylenediaminetetra-acetic acid) tubes from healthy blood donors. The Division of Transfusion Medicine at Erlangen's university hospital (Universitätsklinikum Erlangen) provided the blood residues. The blood was transferred from its collection tubes to a $50 \mathrm{ml}$ centrifuge tube and mixed with phosphate-buffered saline (PBS) to produce equal volumes of $50 \mathrm{ml}$. Fresh $50 \mathrm{ml}$ centrifuge tubes were filled with $15 \mathrm{ml}$ of Lymphoflot (BioRad, Feldkirchen, Germany) each, and we carefully superimposed $12.5 \mathrm{ml}$ of the mixture of blood and PBS on the Lymphoflot. The tubes were centrifuged for 20 $\mathrm{min}$ at $850 \mathrm{~g}$ at room temperature with a low acceleration and with no brake. This process separated the various cell fractions of the blood samples due to the density gradient of Lymphoflot. The rings containing PBMC were transferred to fresh $50 \mathrm{ml}$ centrifuge tubes and mixed with cold PBS-EDTA. The tubes were centrifuged again for $12 \mathrm{~min}$ at $4{ }^{\circ} \mathrm{C}$ and $300 \mathrm{~g}$. The resulting PBMC pellet was resuspended in PBS-EDTA and centrifuged for $12 \mathrm{~min}$ at $4{ }^{\circ} \mathrm{C}$ and $200 \mathrm{~g}$. After these washing steps, we resuspended the PBMC pellet in $50 \mathrm{ml}$ of RPMI Medium with $1 \%$ penicillin/streptomycin antibiotics and 10\% FCS (R-10 Medium) (all from Gibco, Schwerte, Germany). The concentration of PBMC was calculated using a Neubauer counting chamber.

\section{Non-professional phagocytosis assay in vitro}

In previous research, our working group had established a protocol for the study of non-professional phagocytosis of necrotic and apoptotic cells in vitro [50]. We slightly modified this protocol for these experiments to take account of particular characteristics of leukocytes.

For all experiments, PBMC were stained using live dye, CyTRAK orange (Thermo Fisher, Schwerte, Germany). The excess dye was washed off and the target cells were resuspended in R-10 Medium. After staining, PBMC were exposed to hyperthermia at $56^{\circ} \mathrm{C}$ for 40 $\mathrm{min}$ in a water bath. Before co-incubation, adherent host cell layers were washed with medium to remove cell debris. The medium was replaced. Stained and hyperthermia-treated target cells were added to the fresh medium. The 6-well plates were shaken carefully to distribute the target cells evenly on the cover slips. We co-incubated host cells with target cells at $37{ }^{\circ} \mathrm{C}$ in a $5 \%$ $\mathrm{CO}_{2}$ atmosphere.

Initially, we co-incubated the cells for $4 \mathrm{~h}$ and used a 1:1 ratio of target and host cells. After finding a low rate of engulfment of stained, untreated leukocytes after $4 \mathrm{~h}$ of co-incubation, we tested longer co-incubation times $(12 \mathrm{~h}, 48 \mathrm{~h}, 36 \mathrm{~h}, 48 \mathrm{~h})$. We also increased the target-to- 
host cell ratio to $2: 1$ by adding 400,000 target cells to an adherent layer of 200,000 BEAS-2B as host cells. In these experiments, viability and death rates were determined after co-incubation, using stained, otherwise untreated leukocytes.

\section{Variation of treatment prior to co-incubation}

To determine if the cause of cell death impacted the uptake of leukocytes, we varied the treatment applied prior to co-incubation. PBMC were used as target cells and stained with CyTRAK orange. Due to the comparably high phagocytic capacity they had shown in our standard non-professional phagocytosis assay, we chose BEAS-2B as host cells for these experiments. To potentially increase CIC rates and better determine possible differences between the treatments applied prior to co-incubation, we opted for a targetto-host cell ratio of 2:1.

One batch of live stained PBMC was irradiated with $0.5 \mathrm{~Gy}, 1 \mathrm{~Gy}, 2 \mathrm{~Gy}$ or $5 \mathrm{~Gy}$ and then incubated for $18 \mathrm{~h}$ or $36 \mathrm{~h}$ at $37^{\circ} \mathrm{C}$ and $5 \% \mathrm{CO}_{2}$ to allow radiation damage to occur. We determined their viability and co-incubated them for $4 \mathrm{~h}$ with the recipient cells. A further batch of live stained PBMC was exposed to hyperthermia at $44^{\circ} \mathrm{C}$ for $1 \mathrm{~h}$. We compared conventional thermal hyperthermia generated by a water bath to microwave hyperthermia. The system for delivering microwave irradiation at $2.45 \mathrm{GHz}$, as described by Hader et al., enables hyperthermia under controlled conditions in a sterile environment [51]. After exposure to hyperthermia, the PBMC were co-incubated with the recipient cells for $4 \mathrm{~h}$. After this, we determined the viability of the PBMC.

\section{Fluorescent immunocytochemistry}

For further staining, the cells were permeabilised and fixed at room temperature with a solution containing $3.7 \%$ formaldehyde and $0.1 \%$ Triton X-100. We washed the samples with PBS three times. Then, the samples were incubated at $4{ }^{\circ} \mathrm{C}$ overnight with a blocking solution containing 5\% FCS, $0.3 \%$ Triton X-100 and $0.3 \%$ sodium azide in PBS. Primary and secondary antibodies were diluted in a solution containing $0.1 \mathrm{~g}$ bovine serum albumin and $30 \mu \mathrm{l}$ Triton X-100 in PBS. The samples were incubated overnight once again, this time with the primary antibody dilution in a humidity chamber at $4{ }^{\circ} \mathrm{C}$. The next day, the samples were washed three times with PBS and then incubated with the secondary antibody dilutions for $1.5 \mathrm{~h}$ at room temperature in a humidity chamber. Samples were washed three times with PBS again before drying. Dry samples were mounted with Prolong Gold with DAPI (4',6-diamidino-2-phenylindole) (Thermo Fisher, Schwerte, Germany). Supplementary Tables 1 and 2 list the primary and secondary antibodies used for the experiments. Actin was stained using phalloidin conjugated with Alexa Fluor 488 diluted 1:500 to 1:1000. The images were acquired using a fluorescence microscope (Axiolmager Z2, Zeiss, Göttingen, Germany).

\section{Image analysis and $\mathrm{CIC}$ count}

We used Biomas software to analyse the images. Prior to analysis, we marked CIC structures manually on the images. The software then counted the number of marked $\mathrm{CIC}$ structures and the number of host cells. A structure was classified as one CIC if one or more red-stained leukocytes were engulfed by one recipient cell. The process of internalisation deformed the host cell's nucleus, while the leukocytes retained an intact nucleus and a round shape. The CIC rate calculated by the software is the quotient of the number of CIC structures and the number of host cells. CIC rates are expressed as a percentage.

\section{Annexin V-FITC/propidium iodide staining}

For each batch, Annexin V-FITC (BioLegend, San Diego, CA, USA)/propidium iodide (Thermo Fisher, Schwerte, Germany) staining was performed to determine numbers of viable, apoptotic and necrotic leukocytes. $1 \times 10^{5}$ cells were centrifuged and the pellet was resuspended with $0.1 \mu \mathrm{g} / \mathrm{ml}$ Annexin V-FITC and $0.2 \mu \mathrm{g} / \mathrm{ml}$ propidium iodide in Ringer's solution. We incubated the samples for $30 \mathrm{~min}$ at $4{ }^{\circ} \mathrm{C}$ in the dark and subsequently analysed the samples using flow cytometry.

\section{Statistical data analysis}

We used GraphPad Prism version 8 (GraphPad Software, San Diego, CA, USA) for data analysis and plotting. Each assay was performed at least three times. We calculated the mean and the standard deviation of the results. Apoptotic and necrotic cell rates were added together to obtain death rates. As the data did not follow a Gaussian distribution, we calculated the Spearman correlation coefficient. Kruskal-Wallis tests were performed to analyse the phagocytic capacity of the various host cells. We performed Mann-Whitney U-tests to compare the effect of different impact times after irradiation on CIC rates and death rates, depending on the dose applied. We also used Mann-Whitney U-tests to analyse the difference in $\mathrm{CIC}$ rates and death rates after conventional and microwave hyperthermia.

\section{Supplementary Information}

The online version contains supplementary material available at https://doi. org/10.1186/s12860-021-00377-3.

Additional file 1: Table S1. Primary antibodies used for

immunofluorescence staining. Table S2. Secondary antibodies used for immunofluorescence staining. 


\section{Acknowledgements}

The authors would like to thank Doris Mehler, Elisabeth Müller and Kristina Wild for excellent technical support during the experiments. Our special thanks go to all blood donors for their donation and their willingness to allow their samples to be used in the study. The present work was performed by the first author Mareike Bauer in (partial) fulfilment of the requirements for obtaining the degree of "Dr. med.".

\section{Authors' contributions}

MFB performed most of the experiments, analysed the data, and drafted the manuscript. LVRD, MFB, MB-H and MHe contributed to the concept of the study and assessed interim results. MHa performed the microwave experiments. LVRD, MFB and MHa contributed to the study design. LVRD and MFB interpreted the data. LVRD, MB-H, MHe and RF were overall supervisors. All authors contributed to editing the final draft, read and approved the manuscript.

\section{Funding}

The authors received no funding for the conduction of this study. Open Access funding enabled and organized by Projekt DEAL.

\section{Availability of data and materials}

All data generated and analysed in the current study are available from the corresponding author on reasonable request.

\section{Declarations}

\section{Ethics approval and consent to participate}

All blood donors gave their written informed consent to the use of their blood sample for scientific research in the context of this study. The blood used was residue from the blood bank. The Ethics Committee of FriedrichAlexander-Universität Erlangen-Nürnberg approved the study (21_ 19 B).

\section{Consent for publication}

Not applicable.

\section{Competing interests}

The authors declare that they have no competing interests.

\section{Author details}

'Department of Radiation Oncology, Universitätsklinikum Erlangen, Friedrich-Alexander-Universität Erlangen-Nürnberg (FAU), Universitätsstraße 27, D-91054 Erlangen, Germany. ${ }^{2}$ Department of Nephropathology, Institute of Pathology, Universitätsklinikum Erlangen, Friedrich-Alexander-Universität Erlangen-Nürnberg (FAU), Krankenhausstraße 8-10, 91054 Erlangen, Germany.

Received: 8 December 2020 Accepted: 30 June 2021

Published online: 31 July 2021

\section{References}

1. Fais S, Overholtzer M. Cell-in-cell phenomena in cancer. Nat Rev Cancer. 2018;18(12):758-66. https://doi.org/10.1038/s41568-018-0073-9.

2. Green $\mathrm{DR}$, Oguin $\mathrm{TH}$, Martinez J. The clearance of dying cells: table for two. Cell Death Differ. 2016;23(6):915-26. https://doi.org/10.1038/cdd.2015.172.

3. Overholtzer M, Mailleux AA, Mouneimne G, Normand G, Schnitt SJ, King RW et al. A nonapoptotic cell death process, entosis, that occurs by cell-in-cell invasion. Cell. 2007:131(5):966-79. https://doi.org/10.1016/..cell.2007.10.040.

4. Wang M, Niu Z, Qin H, Ruan B, Zheng Y, Ning X, et al. Mechanical ring interfaces between Adherens junction and contractile Actomyosin to coordinate entotic cell-in-cell formation. Cell Rep. 2020;32(8):108071. https:// doi.org/10.1016/j.celrep.2020.108071.

5. Humble JG, Jayne WH, Pulvertaft RJ. Biological interaction between lymphocytes and other cells. Br J Haematol. 1956;2(3):283-94. https://doi. org/10.1111/j.1365-2141.1956.tb06700.x

6. Mackay HL, Muller PAJ. Biological relevance of cell-in-cell in cancers. Biochem Soc Trans. 2019;47(2):725-32. https://doi.org/10.1042/BST20180618.

7. He M, Wang S, Wang Y, Wang X. Modeling cell-in-cell structure into its biological significance. Cell Death Dis. 2013;4(5):e630. https://doi.org/10.103 8/cddis.2013.147.
8. Huang $\mathrm{H}$, Chen Z, Sun Q. Mammalian cell competitions, cell-in-cell phenomena and their biomedical implications. Curr Mol Med. 2015;15(9): 852-60. https://doi.org/10.2174/1566524015666151026101101.

9. Overholtzer M, Brugge JS. The cell biology of cell-in-cell structures. Nat Rev Mol Cell Biol. 2008;9(10):796-809. https://doi.org/10.1038/nrm2504.

10. Clavería C, Giovinazzo G, Sierra R, Torres M. Myc-driven endogenous cell competition in the early mammalian embryo. Nature. 2013;500(7460):39-44. https://doi.org/10.1038/nature12389.

11. Davies SP, Terry LV, Wilkinson AL, Stamataki Z. Cell-in-cell structures in the liver: a tale of four E's. Front Immunol. 2020;11:650. https://doi.org/10.3389/ fimmu.2020.00650.

12. Zhao S-X, Li W-C, Fu N, Zhou G, Liu S-H, Jiang L-N, et al. Emperipolesis mediated by CD8+ T cells correlates with biliary epithelia cell injury in primary biliary cholangitis. J Cell Mol Med. 2020;24(2):1268-75. https://doi. org/10.1111/jcmm.14752.

13. Chen $Y$, Wang S, He M, Wang $Y$, Zhao H, Zhu H, et al. Prevalence of heterotypic tumor/immune cell-in-cell structure in vitro and in vivo leading to formation of aneuploidy. PLoS One. 2013;8(3):e59418. https://doi.org/1 0.1371/journal.pone.0059418.

14. Lugini L, Matarrese $P$, Tinari A, Lozupone F, Federici C, lessi E, et al. Cannibalism of live lymphocytes by human metastatic but not primary melanoma cells. Cancer Res. 2006;66(7):3629-38. https://doi.org/10.1158/ 0008-5472.CAN-05-3204

15. Lozupone F, Fais S. Cancer cell cannibalism: a primeval option to survive. Curr Mol Med. 2015;15(9):836-41. https://doi.org/10.2174/1566524015666151 026100916.

16. Sun Q, Luo T, Ren Y, Florey O, Shirasawa S, Sasazuki T, et al. Competition between human cells by entosis. Cell Res. 2014;24(11):1299-310. https://doi. org/10.1038/cr.2014.138.

17. Wang S, Li L, Zhou Y, He Y, Wei Y, Tao A. Heterotypic cell-in-cell structures in colon cancer can be regulated by IL-6 and lead to tumor immune escape. Exp Cell Res. 2019;382(1):111447. https://doi.org/10.1016/j.yexcr.2019. 05.028

18. Liang J, Niu Z, Zhang B, Yu X, Zheng Y, Wang C, et al. p53-dependent elimination of aneuploid mitotic offspring by entosis. Cell Death Differ. 2021:28(2):799-813. https://doi.org/10.1038/s41418-020-00645-3.

19. Takeuchi M, Inoue T, Otani T, Yamasaki F, Nakamura S, Kibata M. Cell-in-cell structures formed between human cancer cell lines and the cytotoxic regulatory T-cell line HOZOT. J Mol Cell Biol. 2010;2(3):139-51. https://doi. org/10.1093/jmcb/mjq002.

20. Schwegler M, Wirsing AM, Schenker HM, Ott L, Ries JM, Büttner-Herold M, et al. Prognostic value of homotypic cell internalization by nonprofessional phagocytic Cancer cells. Biomed Res Int. 2015;2015:359392.

21. Schenker H, Büttner-Herold M, Fietkau R, Distel LV. Cell-in-cell structures are more potent predictors of outcome than senescence or apoptosis in head and neck squamous cell carcinomas. Radiat Oncol. 2017;12(1):21. https://doi. org/10.1186/s13014-016-0746-z.

22. Mackay HL, Moore D, Hall C, Birkbak NJ, Jamal-Hanjani M, Karim SA, et al. Genomic instability in mutant p53 cancer cells upon entotic engulfment. Nat Commun. 2018;9(1):3070. https://doi.org/10.1038/s414 67-018-05368-1.

23. Hayashi A, Yavas A, Mclntyre CA, Ho Y-J, Erakky A, Wong W, et al. Genetic and clinical correlates of entosis in pancreatic ductal adenocarcinoma. Mod Pathol. 2020;33(9):1822-31. https://doi.org/10.103 8/s41379-020-0549-5.

24. Mlynarczuk-Bialy I, Dziuba I, Sarnecka A, Platos E, Kowalczyk M, Pels KK, et al. Entosis: From Cell Biology to Clinical Cancer Pathology. Cancers (Basel). 2020;12:9.

25. Almangush A, Mäkitie AA, Hagström J, Haglund C, Kowalski LP, Nieminen P, et al. Cell-in-cell phenomenon associates with aggressive characteristics and cancer-related mortality in early oral tongue cancer. BMC Cancer. 2020;20(1): 843. https://doi.org/10.1186/s12885-020-07342-x.

26. Fan J, Fang $Q$, Yang $Y$, Cui $M$, Zhao $M$, Qi J, et al. Role of heterotypic neutrophil-in-tumor structure in the prognosis of patients with buccal mucosa squamous cell carcinoma. Front Oncol. 2020;10:541878. https://doi. org/10.3389/fonc.2020.541878.

27. Huang H, He M, Zhang Y, Zhang B, Niu Z, Zheng Y, et al. Identification and validation of heterotypic cell-in-cell structure as an adverse prognostic predictor for young patients of resectable pancreatic ductal adenocarcinoma. Signal Transduct Target Ther. 2020;5(1):246. https://doi. org/10.1038/s41392-020-00346-w. 
28. Lugini L, Lozupone F, Matarrese P, Funaro C, Luciani F, Malorni W, et al. Potent phagocytic activity discriminates metastatic and primary human malignant melanomas: a key role of ezrin. Lab Investig. 2003;83(11):1555-67. https://doi.org/10.1097/01.LAB.0000098425.03006.42.

29. Seeberg JC, Loibl M, Moser F, Schwegler M, Büttner-Herold M, Daniel C, et al. Non-professional phagocytosis: a general feature of normal tissue cells. Sci Rep. 2019;9(1):11875. https://doi.org/10.1038/s41598-019-48370-3.

30. Lorat Y, Fleckenstein J, Görlinger P, Rübe C, Rübe CE. Assessment of DNA damage by 53PB1 and pKu70 detection in peripheral blood lymphocytes by immunofluorescence and high-resolution transmission electron microscopy. Strahlenther Onkol. 2020;196(9):821-33. https://doi.org/10.1007/s00066-02001576-1.

31. Zahnreich S, Rösler H-P, Schwanbeck C, Karle H, Schmidberger H. Radiationinduced DNA double-strand breaks in peripheral leukocytes and therapeutic response of heel spur patients treated by orthovoltage X-rays or a linear accelerator. Strahlenther Onkol. 2020. https://doi.org/10.1007/s00066-020-01 $662-4$

32. Hinrikus H, Bachmann M, Lass J. Understanding physical mechanism of lowlevel microwave radiation effect. Int J Radiat Biol. 2018;94(10):877-82. https://doi.org/10.1080/09553002.2018.1478158.

33. Rosin A, Hader M, Drescher C, Suntinger M, Gerdes T, Willert-Porada M, et al. Comparative study and simulation of tumor cell inactivation by microwave and conventional heating. COMPEL. 2018;37(6):1893-904. https://doi.org/1 0.1108/COMPEL-03-2017-0144.

34. Kruglik OV, Morgulis II, Khlebopros RG. Effect of microwave electromagnetic radiation (UHF EMR) on tumor cell viability in experiment. Dokl Biochem Biophys. 2013;449(1):66-8. https://doi.org/1 $0.1134 /$ S1607672913020026.

35. Wang S, Guo Z, Xia P, Liu T, Wang J, Li S, et al. Internalization of NK cells into tumor cells requires ezrin and leads to programmed cell-in-cell death. Cell Res. 2009;19(12):1350-62. https://doi.org/10.1038/cr.2009.114.

36. He $M$, Huang $H$, Wang $M$, Chen $A$, Ning $X$, Yu $K$, et al. Fluorescenceactivated cell sorting analysis of heterotypic cell-in-cell structures. Sci Rep. 2015;5(1):9588. https://doi.org/10.1038/srep09588.

37. Fais S. Cannibalism: a way to feed on metastatic tumors. Cancer Lett. 2007; 258(2):155-64. https://doi.org/10.1016/j.canlet.2007.09.014

38. Xia P, Zhou J, Song X, Wu B, Liu X. Di Li et al. Aurora a orchestrates entosis by regulating a dynamic MCAK-TIP150 interaction. J Mol Cell Biol. 2014;6(3): 240-54. https://doi.org/10.1093/jmcb/mju016.

39. Sun Q, Cibas ES, Huang H, Hodgson L, Overholtzer M. Induction of entosis by epithelial cadherin expression. Cell Res. 2014;24(11):1288-98. https://doi. org/10.1038/cr.2014.137.

40. Ning X, Luo T, Chen Z, Sun Q. The physics for the formation of cell-in-cell structures. Curr Mol Med. 2015;15(9):867-72. https://doi.org/10.2174/1 566524015666151026105123.

41. van Epps DE, Potter J, Vachula M, Smith CW, Anderson DC. Suppression of human lymphocyte chemotaxis and transendothelial migration by anti-LFA1 antibody. J Immunol. 1989;143(10):3207-10.

42. Kavanaugh AF, Lightfoot E, Lipsky PE, Oppenheimer-Marks N. Role of CD11/ CD18 in adhesion and transendothelial migration of T cells. Analysis utilizing CD18-deficient T cell clones. J Immunol. 1991;146(12):4149-56.

43. de Rooij J, Kerstens A, Danuser G, Schwartz MA, Waterman-Storer CM. Integrin-dependent actomyosin contraction regulates epithelial cell scattering. J Cell Biol. 2005;171(1):153-64. https://doi.org/10.1083/jcb.2 00506152.

44. Sexton DW, Blaylock MG, Walsh GM. Human alveolar epithelial cells engulf apoptotic eosinophils by means of integrin- and phosphatidylserine receptor-dependent mechanisms: a process upregulated by dexamethasone. J Allergy Clin Immunol. 2001;108(6):962-9. https://doi.org/1 0.1067/mai.2001.119414.

45. Hynes RO. Integrins: versatility, modulation, and signaling in cell adhesion. Cell. 1992;69(1):11-25. https://doi.org/10.1016/0092-8674(92)90115-S.

46. Wagner C, Pioch M, Meyer C, Iking-Konert C, Andrassy K, Hänsch GM. Differentiation of polymorphonuclear neutrophils in patients with systemic infections and chronic inflammatory diseases: evidence of prolonged life span and de novo synthesis of fibronectin. J Mol Med. 2000;78(6):337-45. https://doi.org/10.1007/s001090000107.

47. Kraft $S$, Klemis $V$, Sens $C$, Lenhard $T$, Jacobi $C$, Samstag $Y$, et al. Identification and characterization of a unique role for EDB fibronectin in phagocytosis. J Mol Med. 2016;94(5):567-81. https://doi.org/10.1007/s00109-015-1373-0.
48. Tanoue T, Takeichi M. New insights into fat cadherins. J Cell Sci. 2005;118(Pt 11):2347-53. https://doi.org/10.1242/jcs.02398.

49. Morris LGT, Kaufman AM, Gong Y, Ramaswami D, Walsh LA, Turcan \$̧, et al. Recurrent somatic mutation of FAT1 in multiple human cancers leads to aberrant Wnt activation. Nat Genet. 2013;45(3):253-61. https://doi.org/10.103 8/ng.2538.

50. Schwegler M, Wirsing AM, Dollinger AJ, Abendroth B, Putz F, Fietkau R, et al. Clearance of primary necrotic cells by non-professional phagocytes. Biol Cell. 2015;107(10):372-87. https://doi.org/10.1111/boc.201400090.

51. Hader M, Savcigil DP, Rosin A, Ponfick P, Gekle S, Wadepohl M, et al. Differences of the Immune Phenotype of Breast Cancer Cells after Ex Vivo Hyperthermia by Warm-Water or Microwave Radiation in a Closed-Loop System Alone or in Combination with Radiotherapy. Cancers (Basel). 2020; 12(5):1082.

\section{Publisher's Note}

Springer Nature remains neutral with regard to jurisdictional claims in published maps and institutional affiliations.
Ready to submit your research? Choose BMC and benefit from:

- fast, convenient online submission

- thorough peer review by experienced researchers in your field

- rapid publication on acceptance

- support for research data, including large and complex data types

- gold Open Access which fosters wider collaboration and increased citations

- maximum visibility for your research: over $100 \mathrm{M}$ website views per year

At BMC, research is always in progress.

Learn more biomedcentral.com/submissions 